\title{
Glucose-stimulated insulin secretion: the hierarchy of its multiple cellular and subcellular mechanisms
}

\author{
Paolo Meda • Frans Schuit
}

Received: 19 August 2013 / Accepted: 12 September 2013 /Published online: 11 October 2013

(C) Springer-Verlag Berlin Heidelberg 2013

\begin{abstract}
Glucose-stimulated insulin secretion is ensured by multiple molecular, cellular and tissue events. In this issue of Diabetologia, Low et al (DOI: 10.1007/s00125-013-3019-5) have taken an important new step towards understanding the hierarchical organisation of these events, by monitoring in vitro the individual exocytosis of multiple beta cells within intact mouse islets. The authors show that glucose stimulation markedly increases the number of exocytotic events per cell and, to a lesser extent, the number of beta cells contributing to this event. In this commentary we discuss these novel observations and propose that metabolic and electrical coupling of islet beta cells is responsible for a more homogeneous glucose-induced secretory response of cells in an intact islet as compared with isolated beta cells.
\end{abstract}

Keywords Beta cells $\cdot$ Confocal microscopy $\cdot$ Connexin . Cx36 · Exocytosis · Glucose $\cdot$ Heterogeneity $\cdot$ Insulin release · Pancreatic islets $\cdot$ Secretory granules $\cdot$ Stimulus-secretion coupling

\section{Abbreviation \\ Cx36 Connexin 36}

Glucose-stimulated insulin secretion is the hallmark of a differentiated beta cell, and the early loss of this feature

\section{P. Meda $(\bowtie)$}

Department of Cell Physiology and Metabolism,

University of Geneva, School of Medicine, CMU,

1 rue Michel Servet, CH - 1211 Genève 4, Switzerland

e-mail: Paolo.Meda@unige.ch

F. Schuit $(\bowtie)$

Department of Cellular and Molecular Medicine, Faculty of

Medicine, KU Leuven, Herestraat 49, B3000 Leuven, Belgium

e-mail: Frans.Schuit@med.kuleuven.be is a prominent event in the pathogenesis of type 2 diabetes $[1,2]$. A wealth of data has identified a number of proteins, organelles and cells that interact during this event. Still, the relative contribution of each of these factors, and their hierarchical organisation for the proper control of insulin secretion, remain open questions.

The molecular steps that couple the increment in extracellular glucose to insulin release is now well established (Fig. 1). A rise in circulating glucose is detected by beta cells because the sugar rapidly diffuses through transport proteins into the cytoplasm. Here it is processed, resulting in a rise in free cytosolic $\left[\mathrm{Ca}^{2+}\right]$, which plays a central role in facilitating the two phases of release of the insulin-containing secretory granules, that cumulatively ensure the appropriate level of insulin secretion $[1,2]$. At the tissue level, it remains a matter of debate whether this sequence takes place in all the beta cells of an intact islet. It has also yet to be determined how the response to glucose stimulation is implemented under in vivo conditions, where the effects of sugar are integrated with those of the many other components of a meal, and beta cells are under influence of the nervous, endocrine and microbiome systems [3, 4]. There is evidence that beta cells are heterogeneous in their ability to metabolise glucose [3], synthesise insulin [5] and release the hormone [6]. Thus, glucose-responsive and non-responsive beta cells have been shown to coexist in the absence of obvious differences in the electrophysiogical properties deemed essential for a proper response to glucose [7]. This heterogeneity is preserved over time [8] and is modulated by both acute and chronic glucose stimulation [6-9], supporting the view that all beta cells are not identical with regard to the cellular mechanisms that are activated by glucose stimulation [3, 4]. Given that in situ beta cells interact with each other and other cell types by a variety of mechanisms [3, 4], including by connexin36 (Cx36) gap junction channels that synchronise their glucose-induced electrical activity and $\left[\mathrm{Ca}^{2+}\right]$ transients $[4,10,11]$, some of the intrinsic differences observed between individual 
beta cells may be masked as other beta cells within wild-type islets will compensate (Fig. 1). Still, differences in the ability of beta cells to release insulin during sustained glucose stimulation have been documented in vivo [9]. At the cellular level, it has been documented that glucose elicits the preferential release of newly made secretory granules [12]. However, how these granules are targeted for exocytosis is not fully understood. Because of these uncertainties, it is still unclear to what extent glucose stimulation is accounted for by the increased activity of individual beta cells, the recruitment of larger numbers of secreting cells, more or faster exocytotic events, or a combination of these factors. Also, the hierarchical organisation of these events remains to be determined.

In this issue of Diabetologia, Low et al [13] have taken an in vitro step towards understanding this process. By combining a high spatial and temporal resolution two-photon microscope and an extracellular membrane-impermeant tracer that labels secretory granules upon their fusion to the cell membrane [14], they simultaneously monitored the individual exocytosis activity of multiple beta cells within mouse islets exposed to various glucose concentrations [13]. Having documented that their approach provides estimates consistent with the actual glucose-induced release of insulin (yet not measured from exactly the same islets which were monitored microscopically), they show that glucose stimulation markedly increases the number of exocytotic events per cell and, to a lesser extent, the number of beta cells contributing to this event. Strikingly, both changes were most conspicuous in islets acutely exposed to $8 \mathrm{mmol} / \mathrm{l}$ glucose, a concentration close to the physiological postprandial levels of the sugar [13]. First, these findings confirm the usefulness of this technology for evaluating the functioning of individual beta cells within the native environment of pancreatic islets [14]. Second, they provide further support for the previous observations that insulin secretion does not take place simultaneously and at the same rate in all beta cells $[6,9]$, and that glucose stimulation promotes the recruitment of actively secreting beta cells [3, 5-9]. The findings strengthen the view that beta cells display intrinsic functional differences that decrease with glucose stimulation [3, 4]. The mechanism of this recruitment remains to be understood. Given that $\mathrm{Cx} 36$ channels ensure the electrical and metabolic coupling of stimulated beta cells and the intercellular synchronisation of their glucose-induced $\left[\mathrm{Ca}^{2+}\right]$ transients $[4,10,11]$, it is likely that $\mathrm{Cx} 36$ signalling is implicated (Fig. 1).

The noteworthy novel finding of the study by Low et al [13] is that the incidence of exocytosis of secretory granules is markedly increased by raising the glucose levels from a resting to a postprandial level, and shows a more modest increment with a further increase in environmental glucose [13]. The data identify the frequency of exocytosis as a primary physiological glucose effect, even though they do not unravel the underlying molecular mechanism and they do not identify the type of granule or the region of the cell membrane involved in their release. Further investigations may indicate how the graded and exquisite sensitivity to glucose is selectively lost in the beta cells of type 2 diabetic patients [1, 2]. In turn, this understanding would be expected to stimulate the development of novel targeted drug and cellular therapies. a

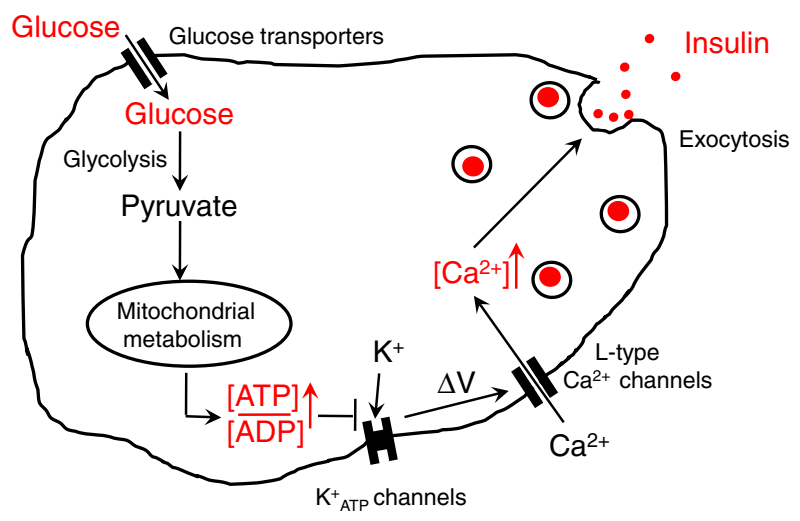

Fig. 1 Molecular and cellular levels of regulation of glucose-stimulated insulin secretion. (a) The intrinsic stimulus-secretion machinery of an adult beta cell starts with the entry of glucose, its glycolytic conversion to pyruvate and its mitochondrial oxidation, which generates ATP. The rise in the ratio of ATP/ADP levels (other coupling factors have been omitted from this figure for simplicity), closes $\mathrm{K}_{\text {ATP }}^{+}$channels, resulting in cell depolarisation, which opens voltage-dependent channels that mediate a rise in the cytosolic $\mathrm{Ca}^{2+}$ concentration. This increase facilitates the exocytosis of insulin-containing granules. (b) In wild-type islets, the response of neighbouring beta cells is modulated by $\mathrm{Cx} 36$ channels. Under basal conditions $(3 \mathrm{mmol} / \mathrm{l}$ glucose, left), these channels couple small numbers of beta cells, which therefore still b
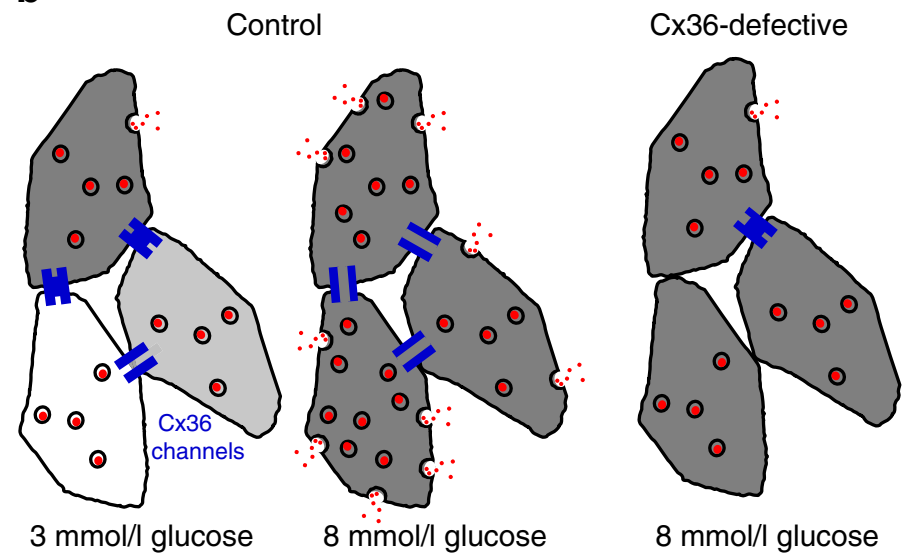

display their native metabolic heterogeneity (indicated by the intensities of the grey shading). As a result, exocytotic events are few, and these are seen in only a minority of metabolically active beta cells (dark grey). After glucose stimulation ( $8 \mathrm{mmol} / \mathrm{l}$ glucose, middle), most beta cells are metabolically activated given the synchronisation facilitated by functional $\mathrm{Cx} 36$ channels. As a result, the number of exocytotic events markedly increases, and a larger proportion of beta cells contribute to insulin secretion. However, when Cx36 channels are poorly expressed or are not functional (right), such intercellular synchronisation cannot take place, in spite of the metabolic activation of most beta cells, resulting in decreased glucose-stimulated insulin secretion 
Still, there are several aspects of the study by Low et al that should be taken into consideration when interpreting these findings. First, the study is on isolated islets [13], leaving the question of whether a similar pattern of exocytosis takes place in vivo to be answered. Further technological developments in conjunction with methods to stimulate individual cells within living animals may help to address this critical issue. Second, and in contrast to previous reports [14], the authors exclude significant effects of glucose on the dynamics of granule opening and recapture. This conclusion may be premature as the experiments were conducted at $34^{\circ} \mathrm{C}$, on islets exposed to only one glucose concentration, and using a monitoring method which, the authors concede, had a time resolution that may not consistently allow the detection of subtle dynamic differences [13]. Third, Low et al propose that the glucose effect on the incidence of exocytosis largely predominates over that on beta cell recruitment. This conclusion should be re-evaluated, taking into account the fact that recordings were made at the periphery of the islets, a region where beta cells are stimulated by glucose at a slower pace than those in the centre of the islets [9], and that the two-photon microscope method imaged only $10 \%$ of the total membrane area of the few dozen beta cells monitored in each recording [13]. Thus, the actual recruitment of the actively secreting beta cells may have been undervalued. This possibility could be tested by combining the novel exocytosis recordings with markers that differentiate between the highly and poorly secreting beta cells, including under conditions such as pregnancy, in which plasticity of the functional beta cell mass is required to accommodate variations in insulin needs [15]. At the end of their paper Low et al comment that the observations made in wild-type murine islets may not apply to human islets [13], because of the several cytological and regulatory differences that have been documented between the two species [16-18]. This is a possibility, even though several similarities have been shown between the islets of the two species, notably with regard to several steps of the glucose-secretion coupling mechanism [1,2], the secretory heterogeneity of individual beta cells [19], their expression of Cx36 channels [20] and their synchronisation within isolated islets [21]. As noted in the conclusion of the paper by Low et al [13], repeating the studies using human islets could help to clarify whether the glucose-induced effects differ in rodents and humans, which may suggest that the differences are dispensable evolutionary modifications, or are similar in the two species, which would argue for some critical, if not obligatory, mechanism.

Funding Supported by grants from the Swiss National Science Foundation (310000-141162, IZ73Z0_127935, CR32I3_129987), the Juvenile Diabetes Research Foundation (1-2010-393, 40-2011-11, 5-2012-281), the European Union (BETAIMAGE 222980; IMIDIA C2008-T7, BETATRAIN 289932), the Flemish Fund For Scientific Research (G.0672.12N) and the KU Leuven (GOA/14/010).
Duality of interest The authors declare that there is no duality of interest associated with this manuscript.

Contribution statement The two authors were responsible for the conception and design of the manuscript, drafting the article and revising it critically for important intellectual content. Both authors approved the version to be published.

\section{References}

1. Henquin JC, Ravier MA, Nenquin M, Jonas JC, Gilon P (2003) Hierarchy of the beta-cell signals controlling insulin secretion. Eur J Clin Invest 33:742-750

2. Rorsman P, Braun M (2013) Regulation of insulin secretion in human pancreatic islets. Annu Rev Physiol 75:155-179

3. Pipeleers D, Kiekens R, Ling Z, Wilikens A, Schuit F (1994) Physiologic relevance of heterogeneity in the pancreatic beta-cell population. Diabetologia 37(Suppl 2):S57-S64

4. Bosco D, Haefliger JA, Meda P (2011) Connexins: key mediators of endocrine function. Physiol Rev 91:1393-1445

5. Schuit FC, In't Veld PA, Pipeleers DG (1988) Glucose stimulates proinsulin biosynthesis by a dose-dependent recruitment of pancreatic beta cells. Proc Natl Acad Sci U S A 85:3865-3869

6. Salomon D, Meda P (1986) Heterogeneity and contact-dependent regulation of hormone secretion by individual B cells. Exp Cell Res 162:507-520

7. Soria B, Chanson M, Giordano E, Bosco D, Meda P (1991) Ion channels of glucose-responsive and -unresponsive beta-cells. Diabetes 40:1069-1078

8. Giordano E, Bosco D, Cirulli V, Meda P (1991) Repeated glucose stimulation reveals distinct and lasting secretion patterns of individual rat pancreatic B cells. J Clin Invest 87:2178-2185

9. Stefan Y, Meda P, Neufeld M, Orci L (1987) Stimulation of insulin secretion reveals heterogeneity of pancreatic B cells in vivo. J Clin Invest 80:175-183

10. Ravier MA, Güldenagel M, Charollais A, Gjinovci A et al (2005) Loss of connexin36 channels alters beta-cell coupling, islet synchronization of glucose-induced $\mathrm{Ca}^{2+}$ and insulin oscillations, and basal insulin release. Diabetes 54:1798-1807

11. Meda P (2012) The in vivo $\beta$-to- $\beta$-cell chat room: connexin connections matter. Diabetes 61:1656-1658

12. Aoyagi K, Ohara-Imaizumi M, Nagamatsu S (2011) Regulation of resident and newcomer insulin granules by calcium and SNARE proteins. Front Biosci 16:1197-1210

13. Low JT, Mitchell JM, Do OH et al (2013) Glucose principally regulates insulin secretion in mouse islets by controlling the numbers of granule fusion events per cell. Diabetologia. doi:10.1007/s00125013-3019-5

14. Takahashi N, Kishimoto T, Nemoto T, Kadowaki T, Kasai H (2002) Fusion pore dynamics and insulin granule exocytosis in the pancreatic islet. Science 297:1349-1352

15. Schraenen A, Lemaire K, de Faudeur G et al (2010) Placental lactogens induce serotonin biosynthesis in a subset of mouse beta cells during pregnancy. Diabetologia 53:2589-2599

16. De Vos A, Heimberg H, Quartier E et al (1995) Human and rat beta cells differ in glucose transporter but not in glucokinase gene expression. J Clin Invest 96:2489-2495

17. Cabrera O, Berman DM, Kenyon NS, Ricordi C, Berggren PO, Caicedo A (2006) The unique cytoarchitecture of human pancreatic islets has implications for islet cell function. Proc Natl Acad Sci U S A 103:2334-2339 
18. Dai C, Brissova M, Hang Y et al (2012) Islet-enriched gene expression and glucose-induced insulin secretion in human and mouse islets. Diabetologia 55:707-718

19. Wojtusciszyn A, Armanet M, Morel P, Berney T, Bosco D (2008) Insulin secretion from human beta cells is heterogeneous and dependent on cell-to-cell contacts. Diabetologia 51:18431852
20. Serre-Beinier V, Bosco D, Zulianello L et al (2009) Cx36 makes channels coupling human pancreatic beta-cells, and correlates with insulin expression. Hum Mol Genet 18:428-439

21. Hellman B, Salehi A, Gylfe E, Dansk H, Grapengiesser E (2009) Glucose generates coincident insulin and somatostatin pulses and antisynchronous glucagon pulses from human pancreatic islets. Endocrinology 150:5334-5340 